\title{
Prednisone 10 days on/10 days off in patients with Duchenne muscular dystrophy
}

\author{
Chiara S. M. Straathof · W. C. G.(Truus) Overweg-Plandsoen • \\ Gert Jan van den Burg • Anneke J. van der Kooi · \\ Jan J. G. M. Verschuuren · Imelda J. M. de Groot
}

Received: 21 February 2008/Revised: 25 September 2008/Accepted: 10 November 2008/Published online: 22 March 2009

(C) The Author(s) 2009. This article is published with open access at Springerlink.com

\begin{abstract}
Corticosteroids are effective in improving motor function in Duchenne muscular dystrophy (DMD) patients within 6 months-2 years of treatment initiation, but there is as yet no consensus on which treatment scheme is the best. We retrospectively analyzed data of $35 \mathrm{DMD}$ patients who were treated with prednisone $0.75 \mathrm{mg} / \mathrm{kg}$ per day intermittently 10 days on/10 days off. Prednisone was started during the ambulant phase at age 3.5-9.7 years (median 6.5 years). The median period of treatment was 27 months (range 3-123 months). The median age at which ambulation was lost was 10.8 years (mean 10.9 years; 95\% confidence interval 10.0-11.8 years). Nine patients (26\%) had excessive weight gain. Eight boys (21\%) had a bone fracture, which was when four of these eight children lost the ability to walk. Treatment was stopped in two obese patients, two hyperactive boys and one patient following a fracture. Our data suggest that prednisone $10 \mathrm{on} / 10$ off has relatively few side effects and extends the ambulant phase by 1 year compared to historical controls.
\end{abstract}

C. S. M. Straathof $(\bowtie)$ · W. C. G. Overweg-Plandsoen .

J. J. G. M. Verschuuren

Department of Neurology, Leiden University Medical Centre,

Leiden, The Netherlands

e-mail: c.s.m.straathof@lumc.nl

G. J. van den Burg

Department of Pediatry, Hospital Gelderse Vallei,

Ede, The Netherlands

A. J. van der Kooi

Department of Neurology, Academic Medical Centre,

Amsterdam, The Netherlands

I. J. M. de Groot

Department of Rehabilitation Medicine, Radboud University

Medical Centre, Nijmegen, The Netherlands
Keywords Muscle disorders · Muscular dystrophy

\section{Introduction}

In 2004, Manzur et al. reported that corticosteroid treatment in Duchenne muscular dystrophy (DMD) effectively improves muscle strength for 6 months -2 years as well as respiratory muscle strength for 6 months [1]. In 2005, guidelines were published in the Netherlands advocating that DMD patients should be treated with $0.75 \mathrm{mg} / \mathrm{kg}$ prednisone daily for at least the ambulant years [2]. This conclusion was based on trials using daily doses of corticosteroids, which proved to be superior to placebo $[3,4]$ and to prednisone on an alternate-day scheme (1 day on/ 1 day off) [5]. Different doses as well as different intermittent schemes of administration have been tried in clinical trials with the aim of reducing side effects [6-10]. However, there is as yet no internationally accepted consensus on which corticosteroid treatment scheme is the best for patients with DMD. In addition, there has yet to be a randomized study involving a head-to-head comparison.

Until 2005, clinical experience with corticosteroid treatment in DMD patients had been scarce in the Netherlands and mainly restricted to a few rehabilitation physicians who prescribed prednisone. In the De Trappenberg rehabilitation center, however, young boys with DMD have been offered prednisone since 1996. The treatment was given in an alternating scheme, 10 days on $/ 10$ days off, in which 10 days prednisone $0.75 \mathrm{mg} / \mathrm{kg}$ per day was alternated with 10 days without corticosteroids; this was in accordance with the dosage scheme of the Hammersmith Hospital in London [11, 12]. This particular therapeutic drug regimen was chosen on the assumption that a sustained clinical effect can be achieved during 
10 days of corticosteroid treatment, while side effects are decreased due to an off phase in which the pituitaryadrenal axis can restore its function. Here, we describe a follow-up study of these young DMD patients who were administered this alternating prednisone therapy, with focus on motor skills and the side effects of prednisone.

\section{Patients and methods}

Patients and clinical data

Between 1996 and 2005, 43 patients with DMD, accompanied by their parents, consulted the De Trappenberg rehabilitation center for treatment with corticosteroids. We have studied the files of these patients retrospectively and evaluated the data. All patients showed progressive muscle weakness typical of DMD, and diagnosis was confirmed by DNA analysis. The rehabilitation physician (IG) and the pediatrician (GJB) performed the clinical monitoring.

The prednisone starting dosage was $0.75 \mathrm{mg} / \mathrm{kg}$ per day in an alternating schema of 10 days on and 10 days off. The treating physician adjusted the dose during growth. In the post-ambulant phase, the dose was lowered to $0.3-$ $0.5 \mathrm{mg} / \mathrm{kg}$ per day 10 days on/10 days off. Two motor assessments were performed prior to the initiation of prednisone treatment and every 6 months thereafter: (1) time to run or walk $10 \mathrm{~m}$ as fast possible; (2) time to stand up from a sitting position on the floor with crossed legs, with the assistance of the hands, but no support from the wall or furniture. The time tests were performed independently of the phase of prednisone therapy. During the clinical visits, body weight, height and blood pressure were measured. Weight gain was interpreted using the standard deviation score (SDS) on a weight-to-height growth chart. On this chart, +2.0 SDS refers to the $P_{98}$ percentile on the reference chart for Dutch children, whereas 0 SDS refers to the $P_{50}$ percentile. Blood pressure was correlated to height and age and interpreted with a reference table [13].

Radiological examinations of the spine in an anteroposterior and lateral direction were performed yearly in order to follow any development of scoliosis and to register subclinical vertebral fractures. The morning serum cortisone level was measured twice yearly during the off period. In the period 1996-2001, cortisone was measured on days 11, 16 and 20 at 0900 and 1600 hours. From 2002 onwards, only the morning cortisone level was measured on day 20 , which is the last day of the off period. All patients received the standard advice of to increase prednisone dose during periods of stress, such as high fever or before surgery. The incidence of bone fractures and the age at which ambulation was lost were registered. Loss of ambulation was defined as being unable to walk unsupported indoors.
Statistical analysis

Descriptive statistics are shown as the median or mean \pm standard deviation (SD). The Kaplan-Meier survival curve of ambulation was calculated with the help of SPSS ver. 12.0 (SPSS, Chicago, IL).

\section{Results}

Clinical data

The median age at which DMD was diagnosed was 4 years (range 9 months-10.4 years), while the median age at the time of evaluation was 10.5 years (range 5-18 years).

Eighteen patients (42\%) were living in the region of the rehabilitation center, and the other 25 patients were seen on a tertiary referral basis. Twenty-five boys (58\%) were attending a regular school, and 18 were attending a special school for children with impaired motor and/or cognitive skills. The parents of four patients decided, after receiving details of the treatment, not to start treatment with prednisone because of behavioral problems (three patients: autism/retardation) or a mild clinical pattern (one patient). Two of the untreated patients became wheelchair bound following a leg fracture due to a trauma at age 11.0 and 12.6 years, respectively. The remaining 39 patients received prednisone for a period of 3-123 months (median 27 months, average 38 months). In four of these patients, prednisone was started during the non-ambulant phase (Fig. 1).

The median age at which prednisone was started was 6.5 years (range 3.5-9.7 years). The dosage of $0.75 \mathrm{mg} / \mathrm{kg}$ was adjusted to body weight during the follow-up, except in four boys because of obesity. After the loss of ambulation, the dosage of prednisone was reduced to $0.3-0.5 \mathrm{mg} / \mathrm{kg}$.

Scoliosis surgery was performed on two patients aged 13.5 and 8 years, respectively. The former had used prednisone for 9 months until he became wheelchair bound

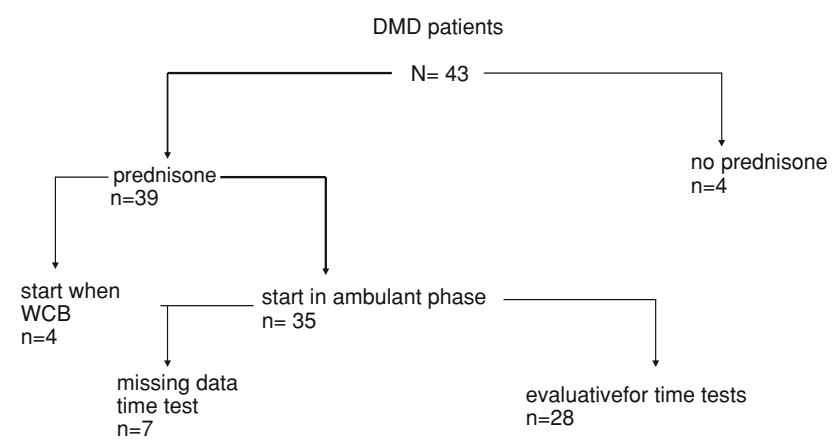

Fig. 1 Flow chart of the treatment scheme for our patient cohort with Duchenne muscular dystrophy (DMD). WCB Wheelchair bound 
(WCB) at age 9.9 years. The second had already lost ambulation at the time of the operation-at age 6.5 years due to a femur fracture. No patient needed respiratory support during the follow-up. Three patients received cardiac medication from their cardiologist.

\section{Motor skills}

\section{Ambulation}

The median age at which ambulation was lost in the 35 prednisone-treated patients was 10.8 years [130 months; mean age 10.9 years, $95 \%$ confidence interval (CI) 10.0 11.8 years; Fig. 2].

\section{Functional scores}

The data obtained in the motor-time tests for 28 treated patients (Fig. 1) was evaluated. The follow-up was $<6$ months in four patients and in two other patients the treatment was stopped due to hyperactivity. During the first months of treatment the time needed to perform the running or standing-up test decreased or remained stable, subsequently increasing when the disease progressed (Fig. 3).

\section{Side effects}

The side effects and complications of prednisone are shown in Table 1. Five patients stopped prednisone

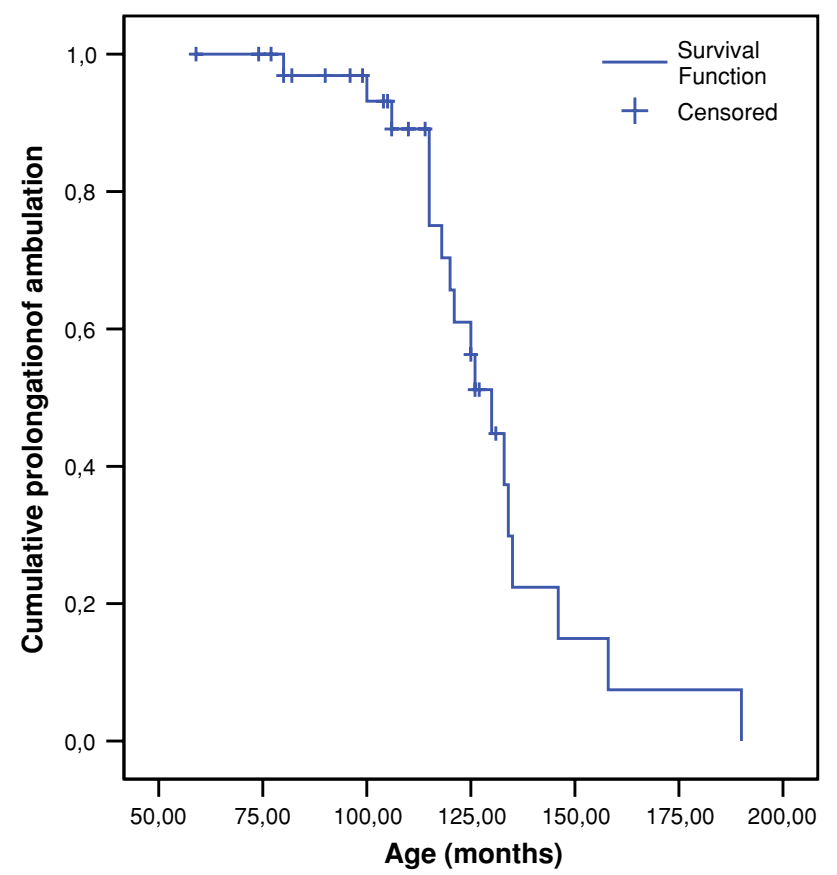

Fig. 2 Cumulative prolongation of ambulation plotted against age of the patient

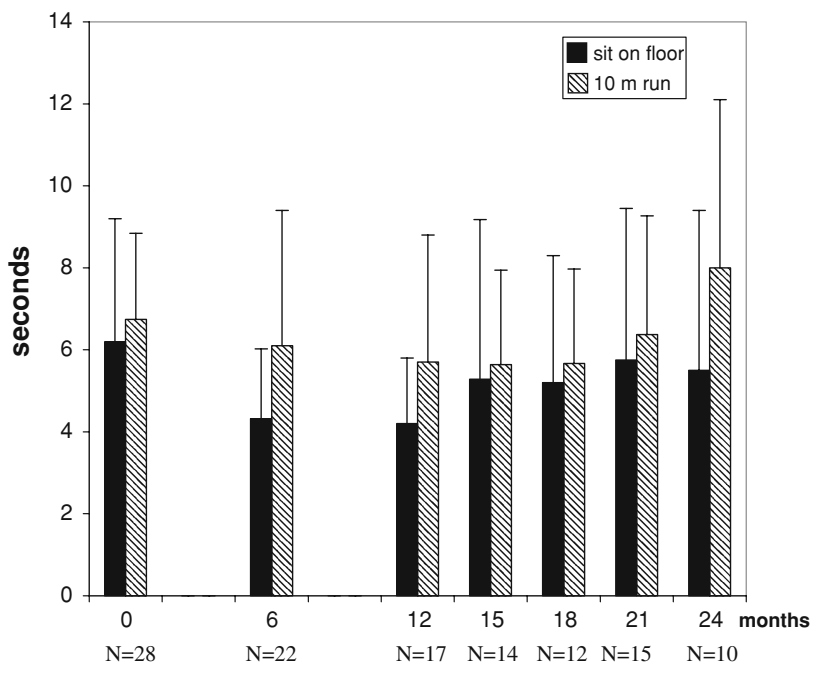

Fig. 3 Results of the motor-time tests during the follow-up of the DMD patient cohort on prednisone

treatment due to the side effects, of whom three had lost ambulation at that time. Eighteen patients $(46 \%)$ showed a weight gain on the weight-to-height growth chart during prednisone treatment (nine patients $\leq 1$ SDS weight gain; nine patients $>1$ SDS weight gain). None of the ambulant boys had a weight gain of more than 1.0 SDS. The body weight in seven DMD patients was already at 1.0 SDS before the start of prednisone treatment.

Eight boys $(21 \%)$ had a fracture during prednisone treatment, with trauma (falling) being the cause of the fracture in six boys; the cause was unknown in the other two boys. All four patients with a femur fracture became WCB due to the fracture. Two boys had a forearm fracture and two others a lower leg fracture. Of the latter, one boy was only temporarily immobilized while the other had lost ambulation 6 months prior to the fracture.

On one occasion, three boys had a systolic blood pressure (SBP) or diastolic blood pressure (DBP) level that was $>95 \%$ percentile after correction for age and height. In two of these children (one boy aged 10 years who had been on prednisone for 5 years, and the other aged 13 years who had been on prednisone for 7.5 years prednisone), the cardiologist also found a diminished ejection fraction on echocardiography; treatment with an angiotensin converting enzyme inhibitor was commenced. In the third boy, high blood pressure was found 3 years after he had stopped taking prednisone; he was given digoxin but data on cardiac function are lacking. The blood pressure in all other patients remained $<95 \%$ percentile during follow-up.

In the first group of 16 patients that received prednisone in the period 1996-2001, serum cortisone levels were very low to nearly zero on the first day without prednisone (day 11), while in all patients the morning level restored to normal before restart of prednisone. From 2002 onwards, 
Table 1 Side effects and complications of prednisone presenting our patients with Duchenne muscular dystrophy

SDS, Standard deviation score

\begin{tabular}{llll}
\hline Side effects/complications & Yes & No & $\begin{array}{l}\text { Reason to stop } \\
\text { prednisone }\end{array}$ \\
\hline $\begin{array}{l}\text { Weight gain }(n=32) \\
\quad \leq 1 \text { SDS }\end{array}$ & 9 & 14 & \\
$\quad>1$ SDS & 9 & 2 \\
Body height $(n=28)$ & & & \\
Average $(0$ SD $)$ & 14 & 12 & 2 \\
$\leq-1$ SD & 14 & & 0 \\
Behavior problems $(n=20)$ & 4 hyperactive & \\
& 4 nycturia & 35 & 1 \\
Adrenal insufficiency day 20 $(n=35)$ & 0 & 27 & \\
Fracture $(n=35)$ & 8 & & \\
\hline
\end{tabular}

morning cortisone levels on day 20 were normal, except in two patients who had a low level of $0.08 \mu \mathrm{mol} / \mathrm{l}$ (reference $0.18-0.72 \mu \mathrm{mol} / \mathrm{l}$ ) on one occasion. None of the patients suffered from adrenal insufficiency during the follow-up period.

\section{Discussion}

Among our pediatric patient group with DMD, the mean age at which patients treated with the 10 on/10 off prednisone scheme became WCB was 10.9 years. Comparable studies in which daily doses of steroids were used have reported a mean age of 11.5 [14] and 12.5 years [15], and those in which alternate-day high-dose prednisone (1.3$2.0 \mathrm{mg} / \mathrm{kg}$ ) were used have reported 14 [16] or 12.2 years [17]. However, a drop-out percentage of $55 \%$ was reported during daily prednisone $0.75 \mathrm{mg} / \mathrm{kg}$ per day due to obesity or infection-related complications [16].

Control patients who were not treated in these nonrandomized studies and DMD patients reported in historical series from 1967 to 2002 became WCB at a mean age of 8.5-12 years [18-20]. The age at which ambulation is lost is a clinical meaningful endpoint for evaluating the efficacy of treatment in DMD patients although it has not been a primary endpoint in randomized studies with steroids in DMD patients up until now [21]. There is no clear consensus on the definition of loss of ambulation. We used a rather practical definition that ambulation was lost if the patient could no longer walk in a household setting [22]. Although the median treatment period was nearly 2 years, the patients in our series had a long-term follow-up which allowed the construction of a Kaplan-Meier survival curve of the prolongation of walking. In four patients of our series, the follow-up of ambulation during steroid treatment was complicated by a leg fracture that resulted in the loss of ambulation. Our study reflects the daily practice of treatment with steroids in DMD. It provides important information when longterm benefits and side effects of steroids are being evalutaed.

In a study in which the inclusion criterion was a minimum of 4 years of treatment with deflazacort in an alternating 20/10 scheme, Biggar et al. [8] reported that $35 \%$ of the patients were still ambulant at age 12 . In young healthy children, functional scores, such as running or standing up from a sitting position on the floor, improve as the child ages from 4 to 10 years due to the growth-related physiological increase in strength [23]. In contrast, DMD patients in the same age group not treated with prednisone showed decreasing mean functional scores during childhood, due to progressive muscle weakness [23]. Although we lack a control group, our patients showed an improvement or stabilization on their functional scores for at least 12 months while on the prednisone 10/10 on/off therapeutic regimen (Fig. 3). Most randomized studies have evaluated corticosteroid treatment using functional scores, with a surprisingly large variation in outcome depending whether a metric or non-metric measure was chosen; for example, time to run has been evaluated in 10 [7, 8], 9 (30 feet) $[4,5,9,10,14,24]$ or $8.54 \mathrm{~m}$ (28 feet) $[11,25]$.

Time to stand up from the floor has also been evaluated starting from a lying position [9, 10], from a sitting position with outstretched legs [7], from a sitting position with crossed legs, or not well defined. This diversity in evaluation endpoints makes it more difficult to compare studies using different schemes or dosages of corticosteroids. The main advantage of treatment with steroids in an alternating scheme instead of daily dose would be a similar efficacy with fewer side effects. In most studies evaluating steroids in DMD, weight gain is an important problem. Studies in which the drug regimen consisted of a daily dose $0.75 \mathrm{mg} /$ $\mathrm{kg}$ per day have reported a weight gain $>10 \%$ in $75 \%$ of the patients [3, 4], while we found a comparable weight gain in only $25 \%$ of our patients and, more remarkably, only in boys after they got WCB. Since seven of the 11 patients that reached a body weight of +2 SDS had a body 
weight of +1 SD before the start of prednisone, the latter seems to be a risk factor for excessive weight gain. In our group, we found that $40 \%$ of the patients did not experience a weight gain, which is comparable to what other researchers have found in a small series of six ambulant DMD patients younger than 5 years [12].

The prevalence of bone fractures in our patients is in accordance with results of a previous study that found $21 \%$ fractures in treated as well as untreated DMD boys [26]. Daily steroid treatment has been reported to increase the risk of long bone fractures by 2.6-fold [15]. The majority of the patients were WCB, which is a risk factor for long bone fractures in untreated neuromuscular patients [26]. Remarkably, we did not find any vertebral fractures in intermittently treated patients, which is in contrast to the reported 32\% compression fractures in the daily steroid treated group [15]. In our DMD cohort hypertension was not a primary problem of intermittent prednisone therapy, although two patients did have a blood pressure $>95 \%$ percentile concomitant with insidious cardiomyopathy.

In conclusion, our data show the results of a long-term follow-up of a large cohort of patients; these data reflect the outcomes observed in daily practice. The retrospective nature of the analysis and the lack of control group limit the interpretation of our results on functional scores. However, controlled studies on the effect of steroids often lack data on long-term endpoints, such as the development of scoliosis and cardiomyopathy. Until better evidence is available on long-term effects, the reporting of observational data can be helpful in terms of making future decisions on the continuation of steroids for DMD patients who have lost ambulation.

Compared to the daily prednisone therapeutic regimens used in other studies, the $10 \mathrm{on} / 10$ off does seem to be effective in extending the ambulant phase in DMD patients; it is also well tolerated. Weight gain is an issue of concern on the 10 on/10 off regimen, especially when ambulation is lost, but it seems to occur less often than when prednisone is administered daily. A prospectively randomized study, with internationally standardized endpoints, would be very useful in providing data for determining the best steroid dose and the best scheme for steroid administration in DMD patients.

Acknowledgments We thank Maaike Monteiro, Diana Belksma and Ellen van Houten of the patient administration in De Trappenberg for their excellent help in retrieving the clinical data. Dr. Frido Dekker freely offered general advice on epidemiological aspects. We thank Prof. Dr. R.A.C. Roos for critical reading of the manuscript.

Open Access This article is distributed under the terms of the Creative Commons Attribution Noncommercial License which permits any noncommercial use, distribution, and reproduction in any medium, provided the original author(s) and source are credited.

\section{References}

1. Manzur AY, Kuntzer T, Pike M, Swan A (2004) Glucocorticoid corticosteroids for Duchenne muscular dystrophy. Cochrane Database Syst Rev 2:CD003725

2. de Groot IJ (2006) Guideline on the use of corticosteroids in Duchenne muscular dystrophy from paediatric neurologists, neurologists and rehabilitation physicians. Ned Tijdschr Geneeskd 150:684-685

3. Mendell JR, Moxley RT, Griggs RC et al (1989) Randomized double blind six-month trial of prednisone in Duchenne's muscular dystrophy. N Eng J Med 320:1592-1597

4. Griggs RC, Moxley RT III, Mendell JR et al (1991) Prednisone in Duchenne dystrophy. Arch Neurol 48:383-388

5. Fenichel GM, Mendell JR, Moxley RTIII (1991) Comparison of daily and alternate-day prednisone therapy in the treatment of Duchenne muscular dystrophy. Arch Neurol 48:575-579

6. Angelini C, Pegoraro E, Turella E, Intino MT, Pini A, Costa C (1994) Deflazacort in Duchenne dystrophy: study of long-term effect. Muscle Nerve 17:386-391

7. Merlini L, Cicognani A, Malaspina E et al (2003) Early prednisone treatment in Duchenne muscular dystrophy. Muscle Nerve 27:222-227

8. Biggar WD, Politano L, Harris VA et al (2004) Deflazacort in Duchenne muscular dystrophy: a comparison of two different protocols. Neuromuscul Disord 14:476-482

9. Connolly AM, Schierbecker J, Renna R, Florence J (2002) High dose weekly oral prednisone improves strength in boys with Duchenne muscular dystrophy. Neuromuscul Disord 12: 917-925

10. Beenakker EAC, Fock JM, Van Tol MJ et al (2005) Intermittent prednisone therapy in Duchenne muscular dystrophy. Arch Neurol 62:128-132

11. Sansome A, Royston P, Dubowitz V (1993) Steroids in Duchenne muscular dystrophy; pilot study of a new low-dosage schedule. Neuromuscul Disord 3:567-569

12. Kinali M, Mercuri E, Main M, Muntoni F, Dubowitz V (2002) An effective, low-dosage, intermittent schedule of prednisolone in the long-term treatment of early cases of Duchenne dystrophy. Neuromuscul Disord 12:S169-S174

13. National High Blood Pressure Education Program Working Group on High Blood Pressure in Children and Adolescents (2004) The fourth report on the diagnosis, evaluation, and treatment of high blood pressure in children and adolescents. Pediatrics 114[Suppl 2]:555-576

14. Balaban B, Matthews DJ, Clayton GH, Carry T (2005) Corticosteroid treatment and functional improvement in Duchenne muscular dystrophy. Long term effect. Am J Phys Med Rehabil 84:843-850

15. King WM, Ruttencutter HM, Nagaraja V et al (2007) Orthopedic outcomes of long-term daily corticosteroid treatment in Duchenne muscular dystrophy. Neurology 68:1607-1613

16. Pradhan S, Ghosh D, Kumar Svrivasta N et al (2006) Prednisolone in Duchenne muscular dystrophy with imminent loss of ambulation. J Neurol 253:1309-1316

17. DeSilva S, Drachman DB, Mellits D, Kuncl RW (1987) Prednisone treatment in Duchenne muscular dystrophy. Arch Neurol $44: 818-822$

18. Emery AEH, Muntoni F (2003) Duchenne muscular dystrophy. Oxford University Press, New York

19. Eagle M, Baudouin SV, Chandler C, Giddings DR, Bullock R, Bushby K (2002) Survival in Duchenne muscular dystrophy: improvements in life expectancy since 1967 and the impact of home nocturnal ventilation. Neuromuscul Disord 12:926-929 
20. Bakker JPJ, de Groot IJM, Beelen A, Lankhorst GJ (2002) Predictive factors of cessation of ambulation in patients with Duchenne muscular dystrophy. Am J Phys Med Rehabil 81:906-912

21. Mendell JR, Csimma C, McDonald CM et al (2007) Challenges in drug development for muscle disease: a stakeholders' meeting. Muscle Nerve 35:8-16

22. Hoffner MM, Feiwel E, Perry J, Bonnet C (1973) Functional ambulation in patients with menongomyelocele. J Bone Joint Surg 55:137-145

23. Beenakker EAC, Maurits NM, Fock JM, Brouwer OF, van der Hoeven JH (2005) Functional ability and muscle force in healthy children and ambulant Duchenne muscular dystrophy patients. Eur J Paediatr Neurol 9:387-393

24. Brooke MH, Fenichel GM, Griggs RC et al (1987) Clinical investigation of Duchenne muscular dystrophy interesting results in a trial of prednisone. Arch Neurol 44:812-817

25. McDonald DG, Kinali M, Gallagher AC et al (2002) Fracture prevalence in Duchenne muscular dystrophy. Dev Med Child Neurol 4:695-698

26. Vestergaard P, Glerup H, Steffensen BF et al (2001) Fracture risk in patients with muscular dystrophy and spinal muscular atrophy. J Rehabil Med 33:150-155 